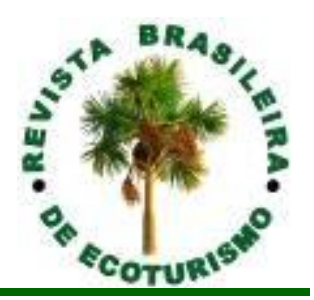

\title{
Quando a simplicidade passa a ser uma opção para a sustentabilidade
}

\author{
Juliana Maria de Barros Freire
}

Elgin, Duane. Simplicidade Voluntária: Em busca de um estilo de vida exteriormente simples, mas interiormente rico. São Paulo: Cultrix, 2012.

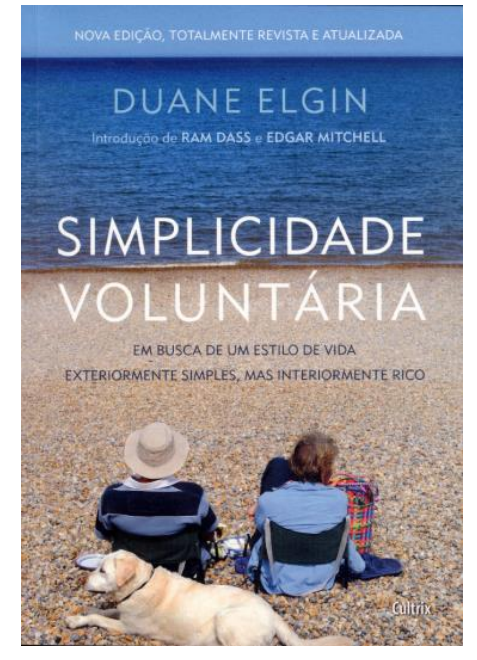

quase 4 décadas.

Seria a adoção - genuína e consciente -, de um modo de vida mais simples e frugal pelos indivíduos da comunidade humana, uma atitude capaz de transformar o mundo num lugar melhor, mais justo e mais sustentável para se viver? Para o autor do livro "Simplicidade Voluntária", Duane Elgin, a resposta é sim. A união de um consumo moderado com consciência ambiental e crescimento pessoal podem promover mudanças na vida das pessoas. Essa é a ideia central que o autor, palestrante, educador, consultor e ativista de mídia, defende há

O conceito de Simplicidade Voluntária não é recente e foi definido, primeiramente por Gregg ${ }^{1}$ em 1936, como "uma pureza, honestidade e sinceridade de propósito que buscasse o distanciamento de comportamentos pautados em posses materiais". Essa utopia foi retomada nos idos do final da década de 1970, quando Duane deu uma palestra a executivos sobre o tema, fez com que ele fosse renegado pelo mundo dos negócios e anunciado como o "MBA de Warthon que perdeu a cabeça". Em 2005, entretanto, quase 30 anos depois, a mesma palestra dada também a um grupo de executivos teve outro impacto. Fez com que o defensor de um estilo simples de viver fosse visto como pioneiro e na vanguarda de uma revolução da sustentabilidade e como o "MBA de Wharton que ficou verde".

A mudança de perspectiva ocorrida desde a publicação da $1^{a}$ edição do livro, em 1981, e a última edição revista em 2009, se deve a uma nova e concreta realidade de problemas enfrentados pela humanidade e sua vida na Terra nos dias de hoje, descritas em vários trechos do livro. $O$ autor defende que viver com simplicidade exterior ajuda a aumentar a riqueza interior das pessoas, como aponta o subtítulo da obra.

Segundo o autor, vivemos numa crise sistêmica, complexa e mundial que afeta todos os aspectos da vida. Mudanças climáticas, esgotamento de 
reserva de petróleo, água e alimentos, extinção de espécies, superpopulação, desigualdade social e consequente violência urbana, entre outros, são uma realidade fabricada pelo atual modo de vida com ênfase no materialismo e consumismo que tem levado ao esgotamento dos recursos do planeta e previsões sombrias para o futuro da existência humana na Terra.

O risco de uma degradação irreversível na capacidade de recuperação do mundo em que vivemos é cada vez mais nítido, e impõe urgência na busca de soluções, não nos permitindo mais ser complacentes com a situação. Ou, nas palavras do próprio autor,

se quisermos manter a integridade da Terra como sistema vivo, precisaremos de uma mudança extrema e criativa que envolva alterações em todos os níveis ou padrões de vida e consumo [...] A simplicidade não é um estilo de vida alternativo para uns poucos escolhidos. É uma opção criativa para a grande maioria, sobretudo nas nações desenvolvidas" (p. 37).

Ele entende que se quisermos avançar juntos como comunidade humana, será crucial que as pessoas adotem uma simplicidade extrema e sofisticada, que tem a ver com escolhas (da pessoa, da civilização e da espécie), como base da sustentabilidade.

Definida em um artigo anteriormente publicado em parceria com Arnold Mitchell intitulado "Voluntary Simplicity"2, o conceito de Simplicidade Voluntária, implica numa modificação do estilo de vida das pessoas rumo a minimização do consumo de bens materiais e, simultaneamente exercitar a autossuficiência, desenvolvendo o intelecto e outros aspectos não materiais inerentes à natureza humana. Trata-se, portanto, basicamente, de uma opção de vida que se opõe aos elevados padrões das sociedades de consumo.

$\mathrm{Na}$ abertura da obra, Raam Dass (Dr. Richard Alpert), em 1980, argumenta que existem atualmente muitas pessoas que já começaram a buscar um equilíbrio mais consciente, "uma simplicidade de vida que permite a integração dos aspectos interior e exterior, material e espiritual, masculino e feminino, pessoal e social, e de todas as outras polaridades que no presente dividem nossa vida" (p. 18). Essa vida mais simples voluntariamente adotada implica em ações com mais deliberação, intenção e propósito, um ser humano mais consciente de si mesmo. Isso "exige não só que estejamos conscientes das escolhas que dispomos (mundo exterior), mas também que estejamos conscientes de nós mesmos ao selecionar essas opções (mundo interior)" (p. 98).

No Capítulo 1 (Estilo de vida frio para um planeta quente), o autor aprofunda a ideia iniciada na introdução, discorrendo sobre a simplicidade e os preconceitos que o termo carrega reforçando que adotar um estilo de vida simples proporciona uma forma mais consciente de viver, pois as intenções e os propósitos podem ser mais bem definidos. Neste ponto, o autor 
apresenta três visões da simplicidade que chamou de "rude/retrógrada", "cosmética/superficial" e "extrema/consciente", sendo que num cenário de crise, esta última a que deveria ser adotada.

Defendendo que a simplicidade não se confunde com viver uma vida de pobreza, nem significa abrir mão dos avanços tecnológicos, ou viver exclusivamente em ambientes bucólicos, acredita que é possível a sociedade alcançar um modo sustentável de vida, mesmo numa grande metrópole, "embora o viver ecológico traga com ele a reverência pela natureza, isso não exige que as pessoas mudem para um cenário rural" ( $p$. 44). O desafio estaria em adotar padrões sustentáveis de consumo, onde as pessoas possam compartilhar recursos, desapegando-se da simples posse de bens materiais. Isso já se observa com o que o autor chamou de "o crescimento da vida verde" ou seja, da comunidade que vem adotando esse estilo de vida.

Em seguida, no capítulo denominado "Pioneiros da vida verde", Elgin apresenta algumas pesquisas realizadas através de depoimentos de diversas pessoas e que revelam uma preocupação cada vez maior com aspectos psicológicos e espirituais. Os entrevistados relataram que obtiveram grandes benefícios ao adotar o novo estilo de vida que, mais do que um afastamento do mundo como o conhecemos, é uma tentativa de construir a civilização sob a inspiração de novos paradigmas, como sustentabilidade, aprimoramento dos relacionamentos, cooperação e integração através de laços afetivos. Há relatos diretos sobre a falsidade, inutilidade e perniciosidade dos valores do consumismo, a satisfação obtida com a mudança de hábitos que permitiram um ganho de tempo para objetivos mais interessantes e elevados, e o aumento de aspectos espirituais como benevolência, gratidão, entre outros.

O terceiro capítulo (Vida Voluntária) o autor sugere que as pessoas devem assumir um efetivo controle de suas ações e pensamentos, evitando reproduções automáticas de comportamentos consumistas e outros, que são fortemente enraizados na cultura da sociedade contemporânea. Trata-se de ampliar a crítica sobre as opções da sociedade de consumo, para aumentar as alternativas de modelos possíveis de convívio. Aqui, a ênfase está na passagem de uma consciência adormecida para uma consciência autorreflexiva ("que nos provê de um espelho capaz de revelar ou refletir, imparcialmente, quem somos na vida cotidiana") (p.105) que promoveria uma comunhão com a vida e, consequentemente, o afloramento de qualidades que ajudariam as pessoas a viver com mais amor e integração com a essência da natureza humana.

Neste capítulo Elgin apresenta com mais concretude a ideia da vida voluntária, utilizando o exemplo de duas pessoas que usam a bicicleta para ir ao trabalho para descrever a diferenças entre as perspectivas pessoais e como elas interferem no estado de espírito. A primeira pessoa usa a bicicleta por opção, por convicção de que esse seu ato é mais saudável e sustentável, e mesmo podendo comprar um carro, segue pedalando por satisfação pessoal. A segunda usa a bicicleta como meio de transporte por necessidade, pois não tem recursos para comprar um carro, o que a deixa frustrada e infeliz. Pedala por obrigação, pois o sonho é ter seu automóvel assim que possível. 
Para efeitos de impacto ambiental, o meio de transporte das duas pessoas é o mesmo (aspecto externo), mas as perspectivas internas são completamente opostas. Para Elgin, são esses aspectos subjetivos e internos que farão a diferença para que a vida com simplicidade possa ser um caminho de equilíbrio entre felicidade humana e harmonia com a natureza. A intenção é o que importa na busca do meio termo entre os extremos de excesso e de miséria. Aquilo que nos é suficiente está entre o que necessitamos (aquilo sem o que não podemos viver) e o que desejamos (normalmente supérfluo e que satisfazem apenas a desejos psicológicos alimentados pela sociedade de consumo). Menos posse de bens e fofocas fúteis sobre a vida alheia e mais autoconhecimento como aprimoramento da capacidade de reforçar relacionamentos e promover crescimento pessoal é a mensagem principal do capítulo.

É no capítulo quatro (Vida simples) que a ele defende a ideia de que viver de modo mais simples alivia o fardo da existência e implica em mais leveza, clareza e liberdade nas relações com os semelhantes, na ligação com a natureza e o planeta, e naquilo que se consome. Trata-se um caminho absolutamente pessoal e intransferível, pois, segundo Elgin, a expressão exterior que a simplicidade assume depende do que cada um entenda o que para si é desnecessariamente complexo. Não há, portanto, um modo único e correto de se viver de modo mais sustentável ou socialmente mais harmônico.

A morte como parte essencial do ciclo da existência, deve ser entendida como uma aliada à compreensão de que nossa finitude nos impõe a valorização dos aspectos intangíveis da vida, em detrimento do que é meramente material e desnecessário. A vida deve ser considerada uma dádiva que cada pessoa precisa administrar com sabedoria e com mais intensidade.

Complementando sua análise da relação do ser humano com os demais elementos do planeta, no capítulo cinco ( $O$ mundo em transição) defende a necessidade de mudanças para uma mentalidade preservacionista em relação à natureza. $\mathrm{O}$ autor denuncia a crise civilizatória que vivemos, com a destruição dos sistemas naturais e o caos no âmbito social, sentenciando que há dois possíveis cenários para o futuro: I Impacto Evolucionário as pessoas não compreenderão o problema e apresentarão soluções superficiais inadequadas, não havendo tempo para uma força total de mudança necessária à sobrevivência da espécie e II Salto Evolucionário - o reconhecimento da necessidade de mudanças faz com que as pessoas usem adequadamente os meios de comunicação de massa para uma compreensão mútua e reconciliação com o modelo partilhado de futuro sustentável.

Nos dois capítulos finais (Simplicidade profunda e a jornada humana e $A$ vida no mundo verde) o autor resgata as visões filosóficas mais clássicas (gregos, orientais, quacres e transcendentalistas) e religiões (cristianismo, islamismo, budismo, hinduísmo e religiões indígenas) para ilustrar "a longa e sólida tradição de simplicidade de vida na experiência espiritual humana" ( $\mathrm{p}$. 157). 
Convidando o leitor a conhecer uma obra sua mais recente (The living Universe), apresenta seis atributos do universo que, juntos o tornariam um "sistema vivo": 1) totalmente unificado, 2) pela maior parte invisível, 3) quantidade imensa de energia de fundo, 4) continuamente se regenerando, 5) consciência em todos os níveis, 6) liberdade desde os fundamentos). Aponta uma crise do consenso em torno de postura coletiva frente a um futuro promissor, no qual os meios de comunicação de massa (televisão e internet) podem e devem ser utilizados para o despertar desse consenso.

Por fim defende que o ser humano tema tendência de reforçar mutuamente as individualidades e que esse atributo gera a megacrise que vivemos. A transição para um mundo verde passaria pelo enfrentamento de oito emergências que desafiam as sociedades contemporâneas: da água, da sustentabilidade, da pobreza, financeira, da extinção, das armas de destruição em massa. Para superar essas emergências contamos com o que ele define como seis "grandes trunfos que podemos mobilizar a fim de transformar nossa era de adversidade numa era de oportunidades" (p.179), devidamente apresentados no último capítulo.

As ideias apresentadas no livro deram origem a um movimento que, apesar de ainda pouco representativo em termos mundiais, vem crescendo na Europa Ocidental e nos Estados Unidos. Elgin mantém um endereço eletrônico do movimento Awakening Earth criado para disseminar seus princípios, onde a filosofia da Simplicidade Voluntária é descrita da seguinte forma:

O mundo está caminhando para uma nova era, em que a
comunidade humana precisa trabalhar junta se quisermos
construir um futuro de prosperidade sustentável. Essa
transição representa um grande desafio e uma
extraordinária oportunidade. Nós estamos sendo chamados
para fazer uma mudança no que tange a estilos de vida
verde, suportados por uma democracia madura e guiados
por uma sabedoria coletiva da ciência e espiritualidade.

Em nosso mundo frenético atual, muito pouco tempo nos resta para refletir sobre o que queremos ou o que de fato precisamos. Fazendo uma relação com o recente crescimento do Ecoturismo, tem-se a dimensão do quanto dependemos do contato com a natureza como fonte de vida.

$\mathrm{Na}$ entrega à experiência direta com a força vital presente em ambientes de vida selvagem, podemos resgatar sentimentos e percepções ancestrais que foram perdidos no nosso processo civilizatório. Uma visita a espaços naturais, que reflita sobre esse processo e o questione, "transforma nosso tradicional comportamento indiferente" 3 . O Ecoturismo, desta forma, é uma prática que se coaduna com a filosofia da Simplicidade Voluntária. 


\section{Notas:}

1 GREGG, R.B. The Value of Voluntary Simplicity. Wallingford, PA: Pendle Hill, 1936.

2 ELGIN, D.; MITCHELL; A. Voluntary Simplicity. The Co-Evolution Quarterly. Sumeer, 1977.

3 NEIMAN, Z.; MENDONÇA, R. Ecoturismo: discurso, desejo e realidade. Turismo em Análise, São Paulo, v.11, n.2, pp.98-110, 2000.

\section{Juliana Maria de Barros Freire}

E-mail: juliana@barrosfreire.adv.br

Link para o currículo Lattes: http://lattes.cnpq.br/1313465743146374

Data de submissão: 02 de setembro de 2013

Data de recebimento de correções: 08 de outubro de 2013

Data do aceite: 08 de outubro de 2013

Avaliado anonimamente 